\title{
The Influence Mechanism and Research of Perceived Risk on Willingness to Pay for Green Agricultural Products
}

\author{
Xueling Kong, Chenchen Chi \\ College of buisness, Jiangxi Normal University, Nanchang 330000, China.
}

Keywords: Perceived risk; Green agricultural products; Brand trust; Willingness to pay.

\begin{abstract}
In order to investigate the influence mechanism of perceived risk on consumers' willingness to pay, this paper, based on the theoretical background of perceived risk, brand trust and willingness to pay, takes green agricultural products as research object, divides perceived risk into six dimensions, and brand trust is divided into two dimensions. This paper tries to verify the mechanism of the different dimensions of perceived risk to the consumers ' willingness to pay under the intermediary action of brand trust. The empirical results show that there are significant negative effects on brand reliability in addition to functional risk. In addition to functional risk and financial risk, there is a significant negative impact on brand intention. Brand reliability and brand intent are significantly affecting consumers ' willingness to pay.
\end{abstract}

\section{Introduction}

The results of the " 2016 China's safe and well-to-do index" survey show that food safety is once again the top ten most worrying safety issues in China. Although our country is a major producer of agricultural products in the world, the brand marketing of agricultural products in our country has just started. most agricultural products brands are only at the level of labeling due to the weak brand awareness of producers and operators and the weak marketing organization. there are not many brands with real fame and value. In recent years, the quality problems of famous brand agricultural products in our country are frequent, and the food crisis has attracted the attention of consumers. The lack of risk and trust has become the main reason that hinders consumers' willingness to pay for green agricultural products. Therefore, it is very important to study the path of perceived risk and willingness to pay.

\section{Literature review}

\subsection{Perceived risk}

In the 1860s, Bauer of Harvard university first applied the concept of perceived risk to the field of marketing. Bauer believed that perceived risk was the uncertainty of consumers' decision-making results on purchase, and this uncertainty of results was perceived risk. he emphasized a kind of subjective risk, which refers to consumers' judgment of subjective awareness of risk before decision making. On this basis, many scholars put forward their own views on the concept of perceived risk. Adopting a broader definition, it is believed that perceived risk is composed of uncertainty before purchase and worries after purchase.

\subsection{Brand trust}

The definition of brand trust in the field of brand management is derived from the research on trust in psychology and sociology. trust we generally believe that it occurs in the relationship between people and organizations. in the discipline of brand management, brand and trust are linked together to promote the establishment of trust relationship between consumers and corporate brands. Many scholars' definitions of multi-brand trust link brand performance expectations. Geok then lau and others defined " brand trust" as " consumers' willingness to trust the brand in the face of risk because they expect the brand to bring positive results". he stressed that in the case of risk, consumers' 
expectation of brand performance and the possibility that the brand will bring positive results are the key points.

\subsection{Willingness to pay for green agricultural products}

Green agricultural products are ecological, safe, high - quality, high-yield and high-efficiency agricultural products produced in specific ways. they are concepts with Chinese characteristics. at present, they include pollution-free agricultural products, green food and organic food, which are certified by specialized agencies and have green or environmental signs. they are referred to as " three kinds of products". these three kinds of agricultural products and food are like a pyramid, and the requirements are stricter as they go up. The definition of willingness to pay in the existing research mainly depends on consumers' acceptance of the highest price.

\section{Research design}

This study is to construct a theoretical model of perceived risk's willingness to pay for green agricultural products based on relevant theoretical research such as perceived risk, brand trust, willingness to pay and so on. Through collecting and analyzing data, the hypotheses in the model are verified, and then the complicated relationships among various variables are clarified.

\subsection{Theoretical model and research hypothesis}

\subsubsection{Theoretical model}

According to the theory of rational behavior, a person's behavior is determined by his will to take actions. therefore, to judge whether a person will take specific actions, one should first understand the degree of his will. As for green agricultural products, few studies have included their perceived risk into the discussion. based on the views of previous scholars, this paper divides perceived risk into six dimensions, namely, functional risk, financial risk, health risk, time risk, channel risk, and emotional risk. based on balles ter's classification of brand trust dimensions, this paper divides it into brand reliability and brand intention, respectively explores the influence of the six dimensions of perceived risk on brand reliability and brand intention, and then analyzes the relationship between brand trust and willingness to pay. The theoretical model of this study is shown in figure 1 .

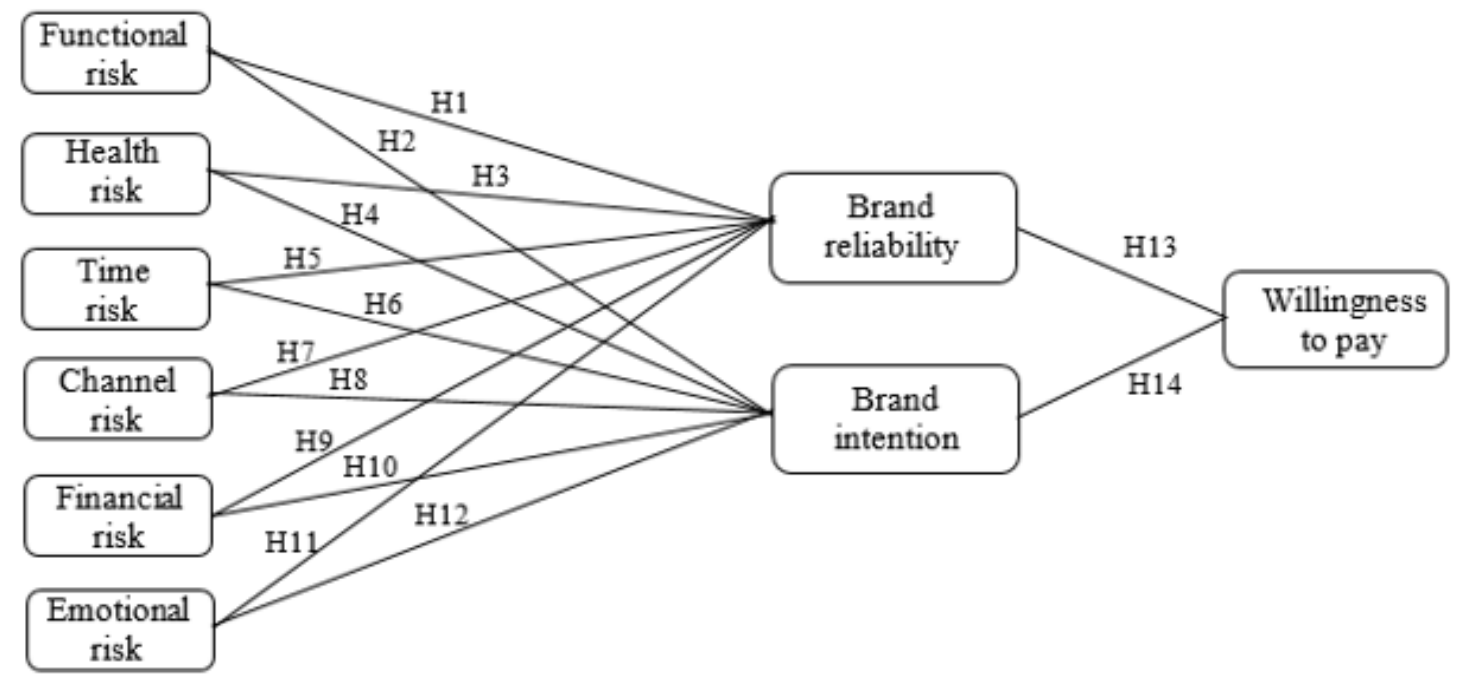

Figure 1 Theoretical framework and assumptions

\subsubsection{Theoretical basis and research hypothesis}

(1)The influence of functional risk on brand trust

Functional risk refers to the consumer's fear that the product's function cannot meet the consumer's needs and cannot meet the consumer's expectations, thus being risky.

H1: Negative effect of functional risk negatively affects consumer's brand reliability 
H2: Functional risk negatively impacts consumer's brand intent

(2)Influence of health risk on brand trust

Health risk refers to the fact that consumers are worried that the products they buy may have some impact on their health or cause potential harm due to quality problems, thus being risky.

H3: Negative impact of health risk negatively on consumer brand reliability

H4: Health risk negatively affects consumers ' brand intentions significantly

(3)Influence of time risk on brand trust

Time risk refers to the risk that consumers are worried about taking a lot of time to choose and compare when choosing products.

H5: Time risk negatively impacts consumer's brand reliability

H6: Time risk negatively affects consumers ' intentions significantly

(4)Influence of channel risk on brand trust

Channel risk refers to consumers' worry that they may buy fake and inferior green agricultural products if they choose improper ways. Due to the particularity of green agricultural products, people cannot identify the accuracy of information with naked eyes. consumers do not know where to buy authentic and safe green agricultural products.

H7: Channel risk negatively affects consumer's brand reliability

H8: Channel risk negatively affects consumer's brand intention significantly

(5)The influence of financial risk on brand trust

Financial risk refers to the difference between the price paid by consumers and the use value of the products obtained, that is, the cost that consumers feel the products are not worth paying and the risk that exists.

H9: Financial risk negatively affects consumer's brand reliability significantly

H10: Financial risk negatively affects consumer's brand intention significantly

(6)Influence of emotional risk on brand trust

Emotional risk refers to the negative, hesitant and discontented emotions that will be brought to consumers' psychology when their purchase results are not good, so there is risk.

H11: Affective risk negatively affects consumer's brand reliability significantly

H12: Affective risk negatively affects consumers ' brand intentions significantly

(7)The influence of brand trust on willingness to pay

According to the existing research, many scholars discussed the influence of brand trust on willingness to pay from different angles. in the study of " the influence of green certification on brand trust and willingness to buy", Yang Xiaoyan and Hu Xiaohong concluded that there is a positive correlation between the degree of trust of green brands and consumers' attitudes and willingness to buy. [34]

H13: Consumer's brand reliability is significantly affecting consumers ' willingness to pay

H14: Consumer's brand intention is positively impacting consumers ' willingness to pay

\subsection{Questionnaire design}

\subsubsection{Data collection}

The data collection of this study is a sampling survey among consumers who bought green agricultural products. The official survey was fully collected through online distribution of questionnaires. a total of 387 consumers participated in the survey, of which 350 were valid questionnaires, 161 were male and 189 were female.

\subsubsection{Measurement of variables}

In order to verify the research hypothesis, this study measures consumers' perceived risk of green agricultural products and the level of impact on their willingness to pay under the premise of perceived risk. Through literature review and interviews, the scale of each variable was designed, then the data were obtained through questionnaire survey, and then the five-point scale was adopted. 


\section{Data analysis}

\subsection{Reliability and validity analysis of data}

Reliability describes the credibility of the sample data, there are four methods of measuring reliability, in this paper, the majority of scholars adopted the Cronbach ' $\mathrm{s}$ a coefficient to measure the scale, We use SPSS24.0 to test the reliability and validity of the samples, each variable test results as shown in table 1 , all the variables of Cronbach ' a value is greater than the $0.8, \mathrm{KMO}$ value is greater than 0.6 , the significant 0.000 is less than 0.001 , indicating that this study of the scale reliability and validity.

Table 1 Reliability and validity test table

\begin{tabular}{|c|c|c|c|c|c|}
\hline \multirow[t]{2}{*}{ Variable } & \multirow[t]{2}{*}{ Cronbach’s a } & \multicolumn{4}{|c|}{ Bartlett's spherical test } \\
\hline & & KMO & X2 & Df & sig \\
\hline $\begin{array}{c}\text { Functional } \\
\text { risk }\end{array}$ & 0.887 & 0.746 & 947.432 & 6 & 0 \\
\hline Health risks & 0.884 & 0.804 & 801.513 & 6 & 0 \\
\hline Time risk & 0.883 & 0.704 & 615.403 & 3 & 0 \\
\hline Channel risk & 0.827 & 0.708 & 397.856 & 3 & 0 \\
\hline Financial risk & 0.839 & 0.698 & 446.606 & 3 & 0 \\
\hline $\begin{array}{c}\text { Emotional } \\
\text { risk }\end{array}$ & 0.890 & 0.809 & 819.467 & 6 & 0 \\
\hline $\begin{array}{c}\text { Brand } \\
\text { reliability }\end{array}$ & 0.835 & 0.774 & 633.474 & 6 & 0 \\
\hline $\begin{array}{c}\text { Brand } \\
\text { intention }\end{array}$ & 0.843 & 0.795 & 583.453 & 6 & 0 \\
\hline $\begin{array}{l}\text { Willingness } \\
\text { to pay }\end{array}$ & 0.827 & 0.799 & 525.290 & 6 & 0 \\
\hline
\end{tabular}

\subsection{Structural equation model test}

In this study, amos 24.0 software was used to test the path of the structural equation model.

\subsubsection{Model fitting}

In this study, amos software was used to analyze the data. the model fitting index is shown in Table 2 from the data in the table, we can know that the model fits well.

Table 2 Structural equation model fitting results

\begin{tabular}{|c|c|c|c|c|c|c|c|c|c|}
\hline Indicators & \multicolumn{4}{|c|}{ Absolute fitting index } & \multicolumn{3}{c|}{ Value - added fitting } & \multicolumn{2}{c|}{$\begin{array}{c}\text { Simple fitting } \\
\text { index } \\
\text { index }\end{array}$} \\
\hline $\begin{array}{c}\text { Specific } \\
\text { classifica- } \\
\text { tion }\end{array}$ & $\begin{array}{c}\text { X2/ } \\
\text { df }\end{array}$ & GFI & RMR & $\begin{array}{c}\text { RMSE } \\
\text { A }\end{array}$ & NFI & TLI & CFI & PGFI & PNFI \\
\hline $\begin{array}{c}\text { Judgment } \\
\text { standard }\end{array}$ & $<3$ & $>0.9$ & $<0.08$ & $<0.08$ & $>0.9$ & $>0.9$ & $>0.9$ & $>0.5$ & $>0.5$ \\
\hline $\begin{array}{c}\text { Fitting } \\
\text { result }\end{array}$ & 1.984 & 0.864 & 0.022 & 0.053 & 0.878 & 0.925 & 0.935 & 0.706 & 0.761 \\
\hline
\end{tabular}

\subsubsection{Model evaluation}

The results of the test of the hypothetical path of the structural equation model are shown in table 2 . This study argues that the path coefficient of the significant level $\mathrm{p}<0.05$ when it is assumed to be tenable. It can be seen from the table that all the other hypotheses are satisfied except the H1,H2,H10, and the independent variables are negative to the mediating variables, and the mediating variables are positive effects on the dependent variables. 


\section{Conclusions and recommendations}

\subsection{Study found}

Based on the research and analysis of this article, the following conclusions can be drawn:

First, functional risk has no significant impact on brand reliability, and other risks are significant. This is because green produce compared with ordinary agricultural products, itself has a high price, healthier characteristics, it will lead to higher consumer expectations of green products. However, as a result of market chaos, the fish dragon mixed bead phenomenon is more and more serious, sometimes consumers spend more money but buy fake green produce, not only can not be beneficial to the health of the expected instead of a certain side effects, which will make consumers in the future purchase of a worried mentality, seriously questioned the authenticity of green agricultural products, The more serious these questions are, the less likely consumers are to be satisfied with their functions.

Second, functional risk and financial risk have no significant impact on brand intention, others are significant. In the event of an emergency, if the consumer has doubts about food health, the concern of the enterprise processing time, consumer concerns about the enterprise after-sales service, whether it can guarantee the legitimate rights and interests of consumers. The result is that consumers have higher health risk, time risk, channel risk, financial risk and emotional risk, which leads to the decrease of trust level of brand intention.

Third, brand reliability and brand intention are significantly affecting consumers ' willingness to pay. The influence of the willingness to pay is higher than the brand intention. This is because trust is a prerequisite for the willingness to pay, if consumers believe that the brand to consumers, believe that the quality of the brand food, will enhance the willingness of consumers to pay.

\subsection{Management advice}

With the improvement of consumers' awareness of food quality and safety, people's willingness to consume green agricultural products has also increased. Perception of risk is the key to influence consumers' willingness to turn consumption into consumption behavior, so how to reduce the uncertainty of consumers is especially important. This paper puts forward the following suggestions for green agricultural products enterprises:

First, the quality of green agricultural products must be guaranteed. Nowadays, food safety incidents occur frequently, and people are paying more and more attention to healthy food. only on the premise of passing through food quality can enterprises have sustained vitality. If the quality of green agricultural products can be guaranteed, the risks of consumers' health, time, channels and feelings will all drop.

Second, the pricing of green agricultural products should be reasonable and regular sales channels should be clearly defined. As the substitution relationship between green agricultural products and ordinary agricultural products is relatively strong, over-pricing will become an obstacle for consumers to further understand green agricultural products. Production enterprises should normalize their sales channels and clearly tell consumers the channels for purchasing their own agricultural products so as to reduce the risk of consumers' channels. at the same time, the establishment of channels should assume certain after-sales responsibilities and set up a complete system to deal with emergencies so as to reduce consumers' psychological anxiety.

Thirdly, establish a brand of green agricultural products to enhance consumers' trust. Good reputation, good word of mouth will reduce consumers' perceived risk. At present, the disorder of the food market, the frequent occurrence of fraud and harm to consumers' health, and consumers' worries about the choice of green agricultural products. Once the brand is established, the consumers' trust will be strengthened and the uncertainty of consumers' choice will be reduced.

\subsection{Research limitations}

This article uses the method of questionnaire survey to measure, which is different from the actual consumption scene of consumers, so it is different from the result of actual decision - making. Secondly, the perceived risk of consumers of green agricultural products in this study is not comprehensive, and there are other risks in real life. 


\section{References}

[1] Sifei Zhang.Present situation and countermeasures of brand marketing of agricultural products in China[J].Journal of wuhanuniversity of technology, 2008, 21(3):341-343.

[2] Bauer R. A Consumer behavior as risk taking. [M]//Hancock R.S(Ed.), Dynamic marketing for a changing world (389-398).Chicago: American Marketing Association,1960.

[3] Yufang Jin, Dahai Dong, Ruiming Liu.Empirical study on the establishment of consumer brand trust mechanism and its influencing factors[J].Nankai business review, 2006(5).

[4] Yanfen Lv.Empirical study on perceived risk structure of green food[J].Tianjin agricultural science, 2011,17(3):77-80.

[5] Pong Qing, Le Wu.Empirical analysis on perceived risk of consumer genetically modified food[J],The influence of science on society, 2010(2):38-41.

[6] Corbitt B J, Thanasankit, Yi H. Trust and e-commerce: a study of consumer perceptions. Electronic Commerce Research and applications 2003, Vol,2:203-215. 